\title{
EZH2 Single Nucleotide Variants (SNVs): Diagnostic and Prognostic Role in 10 Solid Tumor Types
}

\author{
Elisa Paolicchi ${ }^{1, *}$, Lorenzo Fornaro ${ }^{2}$, Stefano Landi ${ }^{1}$, Sushilaben Rigas ${ }^{3}$ \\ and Francesco Crea ${ }^{3, *}$ \\ 1 Genetics, Department of Biology, University of Pisa, Via Derna 1, 56121 Pisa, Italy; stefano.landi@unipi.it \\ 2 Unit of Medical Oncology 2, Azienda Ospedaliero-Universitaria Pisana, University of Pisa, 56126 Pisa, Italy; \\ lorenzo.fornaro@gmail.com \\ 3 School of Life Health \& Chemical Sciences, The Open University, Milton Keynes MK7 6AA, UK; \\ sushila.rigas@open.ac.uk \\ * Correspondence: eli.paolicchi@gmail.com (E.P.); francesco.crea@open.ac.uk (F.C.); \\ Tel.: +44-01908-654834 (F.C.); +39-050-2211530 (E.P.)
}

Academic Editor: Luciano Di Croce

Received: 31 August 2017; Accepted: 30 October 2017; Published: 6 November 2017

\begin{abstract}
The enhancer of zeste homolog 2 (EZH2) gene encodes a histone methyltransferase that is a catalytic subunit of the Polycomb repressive complex 2 (PRC2) group of proteins that act to repress gene expression. The EZH2 locus is rarely mutated in solid tumors and there is no comprehensive study of EZH2 single nucleotide variants (SNVs) associated with cancer susceptibility, prognosis and response to therapy. Here, for the first time, we review the functional roles of EZH2 DNA variants and propose a putative etiological role in 10 various solid tumors including: esophageal, hepatocellular, oral, urothelial, colorectal, lung and gastric cancers. In particular, we found that the $\mathrm{C}$ allele of the EZH2 variant rs 3757441 is associated with increased EZH2 RNA expression and poorer prognosis (advanced stage) in at least two malignancies such as colorectal and hepatocellular carcinoma. This suggests that the $C$ allele may be a functional risk variant in multiple malignant tumors. We therefore propose that the rs3757441 single nucleotide variant (SNV) be genotyped and real-time PCR assays be performed in large cohort studies in order to confirm this preliminary finding that could be useful for clinical practice.
\end{abstract}

Keywords: EZH2; PRC2; single nucleotide variant (SNV); cancers

\section{Introduction}

Polycomb group genes are mainly organized into two multimeric complexes, the Polycomb repressive complex 1 (PRC1) and 2 (PRC2), which are epigenetic repressors in embryonic development, cell fate determination, proliferation, stem cell pluripotency and self-renewal [1]. The enhancer of zeste homolog 2 (EZH2) functions as part of PRC2 by catalyzing the trimethylation of histone $\mathrm{H} 3$ at Lysine 27 (H3K27me3) [2]. This mainly results in Polycomb-dependent chromatin compaction and hence gene silencing [3].

EZH2 is over-expressed in several types of human cancers and its expression is positively correlated with advanced stages of tumor progression and poor clinical outcome [4]. EZH2 over-expression is associated with poor prognosis in anaplastic thyroid carcinoma [5], breast cancer [6], esophageal squamous cell carcinoma (ESCC) [7], gallbladder adenocarcinoma [8], gastric cancer [9], glioma [10], osteosarcoma [11], ovarian cancer [12], prostate cancer [13], renal cell carcinomas [14] and small cell lung cancer [15]. Molecular evidence suggests that EZH2 promotes cancer cell survival, epithelial-to-mesenchymal transition, migration and invasion [16-18], thereby leading to cancer progression and development of metastasis [19,20]. EZH2 somatic mutations are frequent in hematological malignancies (e.g., lymphoma), 
but they are rare in solid tumors including prostate and breast cancers [21]. However, EZH2 expression and functions vary among solid tumor patients.

The EZH2 gene located on chromosome 7q36 encompasses 20 exons, 19 introns, and encodes 2 functional isoforms ( $E Z H 2 \alpha$ and $E Z H 2 \beta$ ) [22]. Within the gene, 41 single nucleotide variants (SNVs) have been identified most of which are in non-coding regions [2]. Emerging evidence indicates that $E Z H 2 \mathrm{SNV}$ influence tumor initiation, progression and therapeutic response. Therefore, EZH2 DNA variants could be used in diagnostics as screening tools (genetic markers) for various cancers, and the gene could be used as a target for novel, personalized drug therapy to enhance cancer care management [23]. In this review, we aim to discuss the functional and putative etiological roles of EZH2 DNA variants in solid tumors.

\section{EZH2 SNVs Associated with Cancer Susceptibility}

Most clinical studies on EZH2 SNVs suggest an association with risk of developing a particular type of cancer (Table 1), but very few have investigated EZH2 protein levels and/or activity. The most studied EZH2 SNVs to potentially predict cancer susceptibility are rs6950683 and rs3757441; carrying the risk T alleles of either rs6950683 or rs3757441 reduces the risk (Odd Ratio: 0.7) of developing oral squamous cell carcinoma susceptibility (OSCC) [24] and particularly small-cell lung cancer (SCLC), when compared to non-small-cell lung cancer patients [25]. Patients carrying the protective $C$ allele at rs3757441 and rs6950683 also showed lower risk of developing hepatocellular carcinoma (HCC) and urothelial carcinomas (UCC), respectively [26,27]. At odds with these studies, the rs3757441 $C$ allele was significantly associated with higher risk of developing ESCC and with higher advanced pathological staging in these tumors [28].

Individuals carrying at the G allele at rs2302427 showed a lower risk of UCC [27]. However, the same genotype at rs2302427 has been associated with higher risks of HCC [29]. Several other EZH2 SNVs have been associated with the risk of developing a specific cancer type in single studies [30,31], (Table 1).

All of these studies indicate that EZH2 SNVs could be useful biomarkers to predict individual susceptibility to specific cancer types. However, since the effect of each SNV seems to be population and cancer and/or tissue specific, large cohort studies are needed, and more evidence on the functional roles of these SNVs. 
Table 1. Enhancer of zeste homolog 2 (EZH2) single nucleotide variants (SNV) associated with cancer susceptibility in different cancer types.

\begin{tabular}{|c|c|c|c|c|c|c|c|c|c|}
\hline SNV & Type of Variant & Risk Allele & Protective Allele & Molecular Function & Cancer & OR & CI 95\% & $p$ Value & Ref \\
\hline rs12670401 & $\mathrm{T}>\mathrm{C}$, intron & C & & & Gastric cancer & 1.327 & $1.075-1.683$ & 0.009 & [31] \\
\hline rs2072407 & $C>T$, intron & $\mathrm{n}$ & TCheterozygote & & Gastric cancer & 0.787 & $0.633-0.981$ & 0.033 & [31] \\
\hline rs6464926 & $C>T$, intron & $\mathrm{T}$ & & & Gastric cancer & 1.310 & $1.059-1.619$ & 0.012 & [31] \\
\hline rs734004 & $G>C$, intron & & CG heterozygote & & Gastric cancer & 0.803 & $0.645-0.999$ & 0.048 & [31] \\
\hline rs734005 & $\mathrm{T}>\mathrm{C}$, intron & & TC heterozygote & & Gastric cancer & 0.799 & $0.642-0.995$ & 0.045 & [31] \\
\hline \multirow[t]{2}{*}{ rs2302427 } & $\begin{array}{c}\mathrm{G}>\mathrm{C} \text {, exon, } \\
\text { missense (D185H) }\end{array}$ & G & & $\begin{array}{l}\text { Concomitant increased expression of CBX8 and BMI1 may } \\
\text { confer risk. PRC1 with PRC2 expression may be protective }\end{array}$ & $\mathrm{HCC}$ & 1.636 & $1.074-2.491$ & 0.021 & [29] \\
\hline & & & GG homozygote & & & 0.388 & $0.168-1.895$ & 0.038 & [27] \\
\hline \multirow[t]{4}{*}{ rs6950683 } & $\mathrm{T}>\mathrm{C}, 5^{\prime} \mathrm{UTR}$ & & C & $\begin{array}{l}\text { Hypermethylation of EZH2 in CC genotype patients } \\
\text { compared to the TC genotype }\end{array}$ & OSCC & 0.791 & $0.66-0.948$ & 0.011 & [24] \\
\hline & & & $\mathrm{C}$ & & $\mathrm{HCC}$ & 0.288 & $0.13-0.638$ & $<0.05$ & [26] \\
\hline & & & - & & Lung cancer & 0.71 & $0.55-0.91$ & 0.007 & [25] \\
\hline & & & $\begin{array}{l}\mathrm{TC}+\mathrm{CC} \\
\text { genotypes }\end{array}$ & & UCC & 0.565 & $0.382-0.835$ & 0.004 & [27] \\
\hline \multirow[t]{4}{*}{ rs3757441 } & $\mathrm{T}>\mathrm{C}$, intron & & $\mathrm{C}$ & & OSCC & 0.820 & $(0.683-0.984)$ & 0.033 & [24] \\
\hline & & & $\mathrm{C}$ & & $\mathrm{HCC}$ & 0.273 & $0.116-0.645$ & $<0.05$ & [26] \\
\hline & & & - & & Lung cancer & 0.73 & $0.57-0.94$ & 0.015 & [25] \\
\hline & & C & & EZH2 and H3K27me3 up-regulation & CRC & & & 0.009 & {$[32,35]$} \\
\hline rs887569 & $C>T$, intron & & TT homozygote & & Bladder cancer & - & - & 0.0146 & [30] \\
\hline
\end{tabular}

(HCC: hepatocellular carcinoma, OSCC: oral squamous cell carcinoma, UCC: urothelial carcinoma, CRC: colorectal cancer). 


\section{EZH2 SNVs Associated with Prognosis and Response to Therapy}

Several of these EZH2 SNVs have been associated with cancer prognosis (Table 2). The C alleles of rs6950683 and rs3757441 may predict a higher risk of developing lymph-node metastasis in HCC [26]. In two independent studies, we found that the $\mathrm{C} / \mathrm{C}$ genotype at rs3757441 was significantly associated with shorter progression free survival (PFS) and overall survival (OS) $(p<0.01$ and $p<0.05$, respectively) in metastatic colorectal cancer $(\mathrm{mCRC})$ patients [32,33]. Interestingly, we also found that the $\mathrm{C} / \mathrm{C}$ genotype (rs3757441) was predictive of poorer response to chemotherapy in mCRC patients. The same genotype was also associated with increased tumor size, poorer differentiation, higher $\mathrm{T}$ stage and higher pathological stage in ESCC patients [28].

Our bioinformatic analyses indicate that the rs $3757441 \mathrm{C}$ allele creates a binding site for the X-Box binding Protein-1 (XBP1) transcription factor [32]. Since the XBP1 transcription factor is associated with an enhancer [34] we have hypothesized that the C allele induces higher EZH2 expression. This hypothesis is corroborated by our findings in colorectal cancer [32] and blood cells, showing that the CC genotype is associated with significantly higher EZH2 expression [35]. Further molecular studies are needed to definitively test this hypothesis. The rs3757441 $\mathrm{C}$ allele is also associated with EZH2 and H3K27me3 up-regulation in primary CRC specimens [35]. Based on these results, it is conceivable that the rs3757441 CC genotype triggers higher EZH2 expression and therefore poorer cancer prognosis, at least in colorectal cancer (CRC) and ESCC cells (Figure 1). It remains to be determined why the same genotype reduces cancer risk in other neoplasms. Notably, this contradictory pattern suggests that the combinations of low penetrance genes make EZH2 either a risk or protective gene, depending on the particular genetic background.

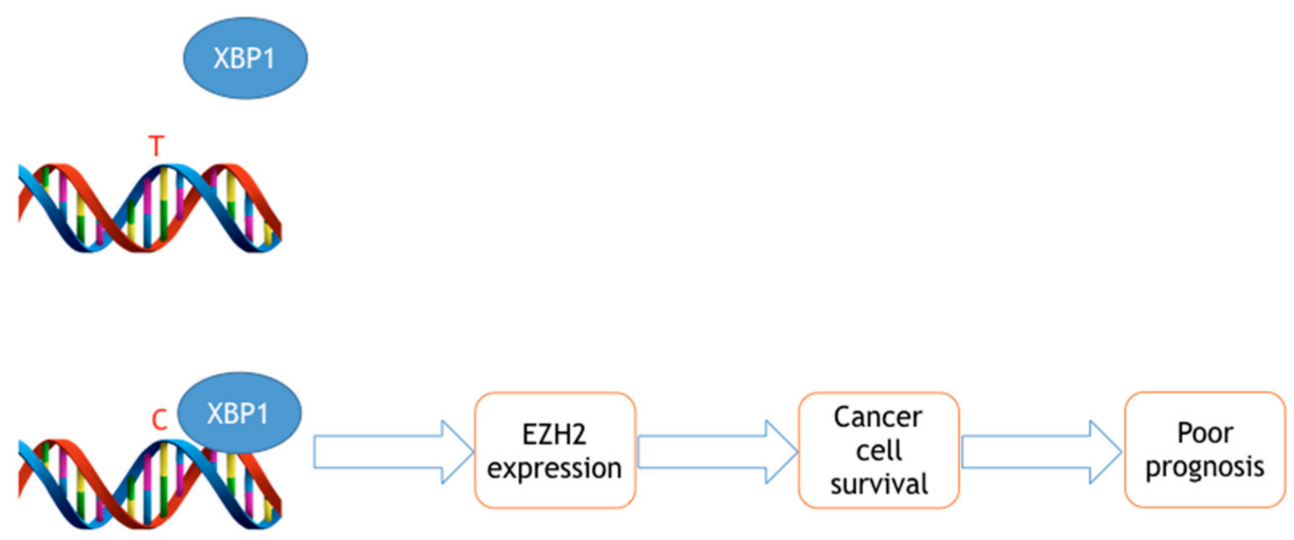

Figure 1. Hypothetical mechanistic role of the rs3757441 SNP in colorectal cancer. The X-Box binding Protein-1 (XBP1) transcription factor only binds to the $\mathrm{C}$ allele, thereby triggering higher EZH2 expression and cancer progression.

Few studies have demonstrated a possible prognostic role for other EZH2 SNVs. For example, the $G$ allele of rs 2302427 has been associated with lower tumor stage in UCC patients [29]. The rs887569 TT genotype was correlated with a significantly longer OS in gallbladder cancer patients, [36] (Table 2).

These data indicate that EZH2 SNVs could predict prognosis and response to therapy in specific cancer types. 
Table 2. EZH2 SNV associated with prognosis and response to therapy. We reported protective/risk alleles wherever possible. When the heterozygous genotype showed higher or lower risk than both homozygous genotypes, we reported full genotypes. Cancer types are abbreviated (UCC: urothelial cell carcinoma, HCC: hepatocellular carcinoma, OSCC: oral squamous cell carcinoma, mCRC: metastatic colorectal cancer, SCLC: small-cell lung cancer, ESCC: esophageal squamous cell carcinoma risk; PFS: progression free survival; OS: overall survival; CI 95\%: confidence interval 95\%).

\begin{tabular}{|c|c|c|c|c|c|c|c|c|}
\hline SNV & Location & Risk Allele & Protective Allele & Clinical Manifestation & Cancer & CI 95\% & $p$ Value & Ref \\
\hline rs2302427 & transcript variant & G & & Increase in invasive tumor stage & UCC & $0.220-0.794$ & $\mathrm{~N} / \mathrm{A}$ & {$[27]$} \\
\hline \multirow[t]{3}{*}{ rs3757441 } & intron & $\mathrm{C}$ & $\mathrm{T}$ & $\begin{array}{l}\text { Higher lymph-node-metastasis risk but a } \\
\text { lower liver-cirrhosis risk }\end{array}$ & $\mathrm{HCC}$ & $1.747-208.155$ & $\mathrm{~N} / \mathrm{A}$ & {$[26]$} \\
\hline & & $\mathrm{C}$ & $\mathrm{T}$ & Shorter PFS and OS & $\mathrm{mCRC}$ & N/A & $<0.01<0.05$ & {$[33]$} \\
\hline & & $\mathrm{C}$ & $\mathrm{T}$ & $\begin{array}{l}\text { Increased risk of tumor size, differentiation, } \\
\text { T stage, and pathological stage }\end{array}$ & ESCC & $\mathrm{N} / \mathrm{A}$ & 0.006 & {$[28]$} \\
\hline rs6950683 & $5^{\prime} \mathrm{UTR}$ & $\mathrm{C}$ & $\mathrm{T}$ & $\begin{array}{l}\text { Higher lymph-node-metastasis risk but a } \\
\text { lower liver-cirrhosis risk }\end{array}$ & $\mathrm{HCC}$ & $1.733-208.866$ & $\mathrm{~N} / \mathrm{A}$ & {$[26]$} \\
\hline rs887569 & intron & $\mathrm{C}$ & $\mathrm{T}$ & Longer OS, reduced risk of mortality & Gallbladder & $0.33-1.05$ & 0.026 & {$[36]$} \\
\hline
\end{tabular}




\section{Conclusions}

This review has identified $10 \mathrm{EZH} 2 \mathrm{SNVs}$ that could potentially predict cancer risk and/or prognosis in 10 types of solid tumors. However, without conducting large cohort studies it is uncertain as to whether these variants are functional in cancer progression or in linkage disequilibrium with a functional variant.

The rs3757441 and rs6950683 SNVs are the most promising diagnostic and functional SNVs to-date. Notably, the T allele of both SNVs has been associated with increased risk of developing four different solid neoplasms, including liver and lung cancers. However, the rs3757441 C allele may be associated with more aggressive phenotypes and poorer prognosis in ESCC and mCRC. Bioinformatic data suggest that the $C$ variant is associated with increased binding of the XBP1 transcription factor and therefore with higher EZH2 expression. We believe that the tissue- and disease-dependent role of the rs3757441 could be explained by the fact that the XBP1 transcription factor is more active/expressed in certain tissues (colon, esophagus) than in others (liver, lung). Where the XBP1 transcription factor is sufficiently expressed, the molecular model proposed in Figure 1 is valid. Where XBP1 levels are very low, other factors could mediate the function of the rs3757441 SNV. Hence, the functional role of the rs3757441 needs to be investigated in different population and cellular contexts, to fully explain its tissue- and disease-specific function.

Furthermore, EZH2 somatic mutations (which are beyond the scope of this review) seem to play a key role in some melanomas. Melanoma is the most frequently EZH2-mutated solid neoplasm [37]. Melanoma cells harbor the Y641 activating mutation within the catalytic SET domain that was first described in Diffuse large B-cell (DLBC) lymphoma. Numerous studies have identified an association between aberrant EZH2 expression and melanoma progression [38]. Although EZH2 SNVs have not been comprehensively investigated in this setting, further translational studies are warranted.

In conclusion, we believe that the clinical usefulness of EZH2 SNVs should prompt the development of more studies in two main directions:

1) Systematic study of the role of all EZH2 SNVs (and their linkage) in specific neoplasms. Ideally, these studies should be prospective and conducted on at least two, independent cohorts if (as we did in $[32,33])$.

2) Functional studies on the role of clinically relevant SNVs, identified in step 1. These studies should be conducted at least in vitro and in human tissues, to confirm the effects of each variant upon EZH2 expression or other function.

EZH2 inhibitors have been shown to be active against a wide range of human neoplasms, and some of these new drugs are being tested in clinical trials $[39,40]$. This emerging evidence reinforces the need for identifying reliable and non-invasive biomarkers to predict the expression and function of EZH2 in patients. These novel diagnostic tools could help predict individual patient response to therapy and identify novel drug therapy targets. Our group and others are currently working on translating these findings into useful clinical applications.

Author Contributions: EP, FC and SR wrote the manuscript. SL and LF critically revised the manuscript.

Conflicts of Interest: The authors declare no conflict of interest.

\section{References}

1. Aloia, L.; Di Stefano, B.; Di Croce, L. Polycomb Complexes in Stem Cells and Embryonic Development. Development 2013, 140, 2525-2534. [CrossRef] [PubMed]

2. Cardoso, C.; Mignon, C.; Hetet, G.; Grandchamps, B.; Fontes, M.; Colleaux, L. The Human EZH2 Gene: Genomic Organisation and Revised Mapping in 7q35 within the Critical Region for Malignant Myeloid Disorders. Eur. J. Hum. Genet. 2000, 8, 174-180. [CrossRef] [PubMed]

3. Mozgova, I.; Hennig, L. The Polycomb Group Protein Regulatory Network. Annu. Rev. Plant Biol. 2015, 66, 269-296. [CrossRef] [PubMed] 
4. Sauvageau, M.; Sauvageau, G. Polycomb Group Proteins: Multi-Faceted Regulators of Somatic Stem Cells and Cancer. Cell Stem Cell 2010, 7, 299-313. [CrossRef] [PubMed]

5. Borbone, E.; Troncone, G.; Ferraro, A.; Jasencakova, Z.; Stojic, L.; Esposito, F.; Hornig, N.; Fusco, A.; Orlando, V. Enhancer of Zeste Homolog 2 Overexpression has a Role in the Development of Anaplastic Thyroid Carcinomas. J. Clin. Endocrinol. Metab. 2011, 96, 1029-1038. [CrossRef] [PubMed]

6. Kleer, C.G.; Cao, Q.; Varambally, S.; Shen, R.; Ota, I.; Tomlins, S.A.; Ghosh, D.; Sewalt, R.G.; Otte, A.P.; Hayes, D.F.; et al. Chinnaiyan, A.M. EZH2 is a Marker of Aggressive Breast Cancer and Promotes Neoplastic Transformation of Breast Epithelial Cells. Proc. Natl. Acad. Sci. USA 2003, 100, 11606-11611. [CrossRef] [PubMed]

7. Liu, F.; Gu, L.; Cao, Y.; Fan, X.; Zhang, F.; Sang, M. Aberrant Overexpression of EZH2 and H3K27me3 Serves as Poor Prognostic Biomarker for Esophageal Squamous Cell Carcinoma Patients. Biomarkers 2016, 21, 80-90. [CrossRef] [PubMed]

8. Liu, D.C.; Yang, Z.L. Overexpression of EZH2 and Loss of Expression of PTEN is Associated with Invasion, Metastasis, and Poor Progression of Gallbladder Adenocarcinoma. Pathol. Res. Pract. 2011, 207, 472-478. [CrossRef] [PubMed]

9. He, L.J.; Cai, M.Y.; Xu, G.L.; Li, J.J.; Weng, Z.J.; Xu, D.Z.; Luo, G.Y.; Zhu, S.L.; Xie, D. Prognostic Significance of Overexpression of EZH2 and H3k27me3 Proteins in Gastric Cancer. Asian Pac. J. Cancer Prev. 2012, 13, 3173-3178. [CrossRef] [PubMed]

10. Zhang, Y.; Yu, X.; Chen, L.; Zhang, Z.; Feng, S. EZH2 Overexpression is Associated with Poor Prognosis in Patients with Glioma. Oncotarget. 2016. [CrossRef] [PubMed]

11. Sun, R.; Shen, J.; Gao, Y.; Zhou, Y.; Yu, Z.; Hornicek, F.; Kan, Q.; Duan, Z. Overexpression of EZH2 is Associated with the Poor Prognosis in Osteosarcoma and Function Analysis Indicates a Therapeutic Potential. Oncotarget 2016, 7, 38333-38346. [CrossRef] [PubMed]

12. Hu, S.; Yu, L.; Li, Z.; Shen, Y.; Wang, J.; Cai, J.; Xiao, L.; Wang, Z. Overexpression of EZH2 Contributes to Acquired Cisplatin Resistance in Ovarian Cancer Cells in Vitro and in Vivo. Cancer Biol. Ther. 2010, 10, 788-795. [CrossRef] [PubMed]

13. Melling, N.; Thomsen, E.; Tsourlakis, M.C.; Kluth, M.; Hube-Magg, C.; Minner, S.; Koop, C.; Graefen, M.; Heinzer, H.; Wittmer, C.; et al. Overexpression of Enhancer of Zeste Homolog 2 (EZH2) Characterizes an Aggressive Subset of Prostate Cancers and Predicts Patient Prognosis Independently from pre- and Postoperatively Assessed Clinicopathological Parameters. Carcinogenesis 2015, 36, 1333-1340. [CrossRef] [PubMed]

14. Wang, Y.; Chen, Y.; Geng, H.; Qi, C.; Liu, Y.; Yue, D. Overexpression of YB1 and EZH2 are Associated with Cancer Metastasis and Poor Prognosis in Renal Cell Carcinomas. Tumor Biol. 2015, 36, 7159-7166. [CrossRef] [PubMed]

15. Sato, T.; Kaneda, A.; Tsuji, S.; Isagawa, T.; Yamamoto, S.; Fujita, T.; Yamanaka, R.; Tanaka, Y.; Nukiwa, T.; Marquez, V.E.; et al. PRC2 Overexpression and PRC2-Target Gene Repression Relating to Poorer Prognosis in Small Cell Lung Cancer. Sci. Rep. 2013, 3, 1911. [CrossRef] [PubMed]

16. Luo, H.; Jiang, Y.; Ma, S.; Chang, H.; Yi, C.; Cao, H.; Gao, Y.; Guo, H.; Hou, J.; Yan, J.; Sheng, Y.; Ren, X. EZH2 Promotes Invasion and Metastasis of Laryngeal Squamous Cells Carcinoma via Epithelial-Mesenchymal Transition Through H3K27me3. Biochem. Biophys. Res. Commun. 2016, 479, 253-259. [CrossRef] [PubMed]

17. Cardenas, H.; Zhao, J.; Vieth, E.; Nephew, K.P.; Matei, D. EZH2 Inhibition Promotes Epithelial-to-Mesenchymal Transition in Ovarian Cancer Cells. Oncotarget 2016, 7, 84453-84467. [CrossRef] [PubMed]

18. Chang, J.W.; Gwak, S.Y.; Shim, G.A.; Liu, L.; Lim, Y.C.; Kim, J.M.; Jung, M.G.; Koo, B.S. EZH2 is Associated with Poor Prognosis in Head-and-Neck Squamous Cell Carcinoma via Regulating the Epithelial-to-Mesenchymal Transition and Chemosensitivity. Oral Oncol. 2016, 52, 66-74. [CrossRef] [PubMed]

19. Cao, Q.; Yu, J.; Dhanasekaran, S.M.; Kim, J.H.; Mani, R.S.; Tomlins, S.A.; Mehra, R.; Laxman, B.; Cao, X.; $\mathrm{Yu}$, J.; et al. Repression of E-Cadherin by the Polycomb Group Protein EZH2 in Cancer. Oncogene 2008, 27, 7274-7284. [CrossRef] [PubMed]

20. Herranz, N.; Pasini, D.; Díaz, V.M.; Francí, C.; Gutierrez, A.; Dave, N.; Escrivà, M.; Hernandez-Muñoz, I.; Di Croce, L.; Helin, K.; et al. Polycomb Complex 2 is Required for E-Cadherin Repression by the Snail1 Transcription Factor. Mol. Cell. Biol. 2008, 28, 4772-4781. [CrossRef] [PubMed] 
21. Crea, F.; Sun, L.; Pikor, L.; Frumento, P.; Lam, W.L.; Helgason, C.D. Mutational Analysis of Polycomb Genes in Solid Tumours Identifies PHC3 Amplification as a Possible Cancer-Driving Genetic Alteration. Br. J. Cancer 2013, 109, 1699-1702. [CrossRef] [PubMed]

22. Grzenda, A.; Lomberk, G.; Svingen, P.; Mathison, A.; Calvo, E.; Iovanna, J.; Xiong, Y.; Faubion, W.; Urrutia, R. Functional Characterization of EZH2 $\beta$ Reveals the Increased Complexity of EZH2 Isoforms Involved in the Regulation of Mammalian Gene Expression. Epigenetics Chromatin 2013, 6, 3. [CrossRef] [PubMed]

23. Seim, N.B.; Kang, S.Y.; Bhandari, M.; Jones, R.G.; Teknos, T.N. Personalized Medicine Approach for an Exceptional Response to Multiple-recurrent and Metastatic HER2-Positive Oropharyngeal Squamous Cell Carcinoma. Ann. Otol. Rhinol. Laryngol. 2017, 126, 334-339. [CrossRef] [PubMed]

24. Su, K.J.; Lin, C.W.; Chen, M.K.; Yang, S.F.; Yu, Y.L. Effects of EZH2 Promoter Polymorphisms and Methylation Status on Oral Squamous Cell Carcinoma Susceptibility and Pathology. Am. J. Cancer Res. 2015, 5, 3475-3484. [PubMed]

25. Yoon, K.A.; Gil, H.J.; Han, J.; Park, J.; Lee, J.S. Genetic Polymorphisms in the Polycomb Group Gene EZH2 and the Risk of Lung Cancer. J. Thorac. Oncol. 2010, 5, 10-16. [CrossRef] [PubMed]

26. Yu, Y.L.; Su, K.J.; Hsieh, Y.H.; Lee, H.L.; Chen, T.Y.; Hsiao, P.C.; Yang, S.F. Effects of EZH2 Polymorphisms on Susceptibility to and Pathological Development of Hepatocellular Carcinoma. PLoS ONE 2013, 8, e74870. [CrossRef] [PubMed]

27. Yu, Y.L.; Su, K.J.; Hsieh, M.J.; Wang, S.S.; Wang, P.H.; Weng, W.C.; Yang, S.F. Impact of EZH2 Polymorphisms on Urothelial Cell Carcinoma Susceptibility and Clinicopathologic Features. PLoS ONE 2014, 9, e93635. [CrossRef] [PubMed]

28. Ma, Z.B.; Guo, G.H.; Niu, Q.; Shi, N. Role of EZH2 Polymorphisms in Esophageal Squamous Cell Carcinoma Risk in Han Chinese Population. Int. J. Mol. Sci. 2014, 15, 12688-12697. [CrossRef] [PubMed]

29. Gao, S.B.; Sun, S.L.; Zheng, Q.L.; Zhang, L.; Zhu, Y.; Jin, G.H.; Xue, L.X. Genetic Alteration and Misexpression of Polycomb Group Genes in Hepatocellular Carcinoma. Am. J. Cancer Res. 2015, 5, 2969-2979. [PubMed]

30. Chang, W.S.; Liao, C.H.; Tsai, C.W.; Hu, P.S.; Wu, H.C.; Hsu, S.W.; Hsiao, C.L.; Hsu, C.H.; Hung, Y.W.; Bau, D.T. Association of Enhancer of Zeste 2 (EZH2) Genotypes with Bladder Cancer Risk in Taiwan. Anticancer Res. 2016, 36, 4509-4514. [CrossRef] [PubMed]

31. Zhou, Y.; Du, W.D.; Wu, Q.; Liu, Y.; Chen, G.; Ruan, J.; Xu, S.; Yang, F.; Zhou, F.S.; Tang, X.F.; et al. EZH2 Genetic Variants Affect Risk of Gastric Cancer in the Chinese Han Population. Mol. Carcinog. 2014, 53, 589-597. [CrossRef] [PubMed]

32. Crea, F.; Fornaro, L.; Paolicchi, E.; Masi, G.; Frumento, P.; Loupakis, F.; Salvatore, L.; Cremolini, C.; Schirripa, M.; Graziano, F.; et al. An EZH2 Polymorphism is Associated with Clinical Outcome in Metastatic Colorectal Cancer Patients. Ann. Oncol. 2012, 23, 1207-1213. [CrossRef] [PubMed]

33. Fornaro, L.; Crea, F.; Masi, G.; Paolicchi, E.; Loupakis, F.; Graziano, F.; Salvatore, L.; Ronzoni, M.; Ricci, V.; Cremolini, C.; et al. EZH2 Polymorphism and Benefit from Bevacizumab in Colorectal Cancer: Another Piece to the Puzzle. Ann. Oncol. 2012, 23, 1370-1371. [CrossRef] [PubMed]

34. Matsuzaki, Y.; Fujisawa, J.; Yoshida, M. Identificational Activation Domain of TREB5, a CREB/ATF Family Protein that Binds to HTLV-1 Enhancer. J. Biochem. 1995, 117, 303-308. [CrossRef] [PubMed]

35. Fornaro, L.; Faviana, P.; De Gregorio, V.; Vivaldi, C.; Paolicchi, E.; Masi, G.; Loupakis, F.; Sensi, E.; Lupi, C.; Fontanini, G.; et al. Molecular and Pathological Characterization of the EZH2 rs3757441 Single Nucleotide Polymorphism in Colorectal Cancer. BMC Cancer 2015, 15, 874. [CrossRef] [PubMed]

36. Paolicchi, E.; Pacetti, P.; Giovannetti, E.; Mambrini, A.; Orlandi, M.; Crea, F.; Romani, A.A.; Tartarini, R.; Danesi, R.; Peters, G.J.; et al. A Single Nucleotide Polymorphism in EZH2 Predicts overall Survival Rate in Patients with Cholangiocarcinoma. Oncol. Lett. 2013, 6, 1487-1491. [CrossRef] [PubMed]

37. Tiffen, J.; Wilson, S.; Gallagher, S.J.; Hersey, P.; Filipp, F.V. Somatic Copy Number Amplification and Hyperactivating Somatic Mutations of EZH2 Correlate with DNA Methylation and Drive Epigenetic Silencing of Genes Involved in Tumor Suppression and Immune Responses in Melanoma. Neoplasia 2016, 18, 121-132. [CrossRef] [PubMed]

38. Mahmoud, F.; Shields, B.; Makhoul, I.; Hutchins, L.F.; Shalin, S.C.; Tackett, A.J. Role of EZH2 Histone Methyltransferase in Melanoma Progression and Metastasis. Cancer Biol. Ther. 2016, 17, 579-591. [CrossRef] [PubMed] 
39. Crea, F.; Fornaro, L.; Bocci, G.; Sun, L.; Farrar, W.L.; Falcone, A.; Danesi, R. EZH2 Inhibition: Targeting the Crossroad of Tumor Invasion and Angiogenesis. Cancer Metastasis Rev. 2012, 31, 753-761. [CrossRef] [PubMed]

40. Vaswani, R.G.; Gehling, V.S.; Dakin, L.A.; Cook, A.S.; Nasveschuk, C.G.; Duplessis, M.; Iyer, P.; Balasubramanian, S.; Zhao, F.; Good, A.C.; et al. Identification of (R)-N-((4-Methoxy-6-methyl-2-oxo-1,2dihydropyridin-3-yl)methyl)-2-methyl-1-(1-(1-(2,2,2-trifluoroethyl)piperidin-4-yl)ethyl)-1H-indole-3carboxamide (CPI-1205), a Potent and Selective Inhibitor of Histone Methyltransferase EZH2, Suitable for Phase I Clinical Trials for B-Cell Lymphomas. J. Med. Chem. 2016, 59, 9928-9941. [PubMed] 